\section{Commentary: Light on the long shadow of systolic anterior motion}

\author{
Tomasz A. Timek, MD, PhD
}

Systolic anterior motion (SAM) of the mitral valve is an integral component of left ventricular outflow tract (LVOT) obstruction that is central to obstructive hypertrophic cardiomyopathy (HCM). Although septal hypertrophy has been the main target of surgical therapy in patients with symptomatic HCM, associated abnormalities of the mitral valve apparatus are increasingly recognized as contributing factors. ${ }^{1}$ Mitral leaflet length has been shown to be associated with incidence of postoperative SAM and LVOT obstruction after degenerative valve repair, ${ }^{2}$ and similar observations have been made in patients with HCM. ${ }^{3}$ These data have spurred some investigators to introduce anterior leaflet-altering procedures ${ }^{4}$ during concomitant septal myectomy to facilitate relief of LVOT obstruction, yet their necessity or effectiveness is unclear. In this issue of the Journal, Carvalho and colleagues ${ }^{5}$ from the Mayo Clinic report on anterior leaflet measurements in 564 patients with HCM undergoing septal myectomy. The investigators found the anterior mitral leaflet in these patients to be longer than in patients undergoing coronary artery bypass grafting or atrial valve replacement procedures. However, anterior leaflet length was not related to preoperative resting LVOT gradients or gradient reduction after isolated myectomy. These data suggest that additional leaflet procedures beyond an extended myectomy may not be needed to relieve outflow obstruction in patients with HCM.

Anterior leaflet length has been reported to be significantly longer in patients with HCM versus age-matched controls, ${ }^{3}$ with longer leaflets found in patients with obstructive versus nonobstructive HCM by some investigators $^{6}$ but not others. ${ }^{7}$ Recent echocardiographic study

From the Division of Cardiothoracic Surgery, Spectrum Health, Michigan State University College of Human Medicine, Grand Rapids, Mich.

Disclosures: The author reported no conflicts of interest.

The Journal policy requires editors and reviewers to disclose conflicts of interest and to decline handling or reviewing manuscripts for which they may have a conflict of interest. The editors and reviewers of this article have no conflicts of interest

Received for publication Feb 5, 2021; revisions received Feb 5, 2021; accepted for publication Feb 8, 2021; available ahead of print Feb 19, 2021.

Address for reprints: Tomasz A. Timek, MD, PhD, Division of Cardiothoracic Surgery, Spectrum Health, Michigan State University College of Human Medicine, 100 Michigan Ave NE, Grand Rapids, MI 49503 (E-mail: tomasz.timek@ spectrumhealth.org).

J Thorac Cardiovasc Surg 2023;165:92-3

$0022-5223 / \$ 36.00$

Copyright (c) 2021 by The American Association for Thoracic Surgery

https://doi.org/10.1016/j.jtcvs.2021.02.049
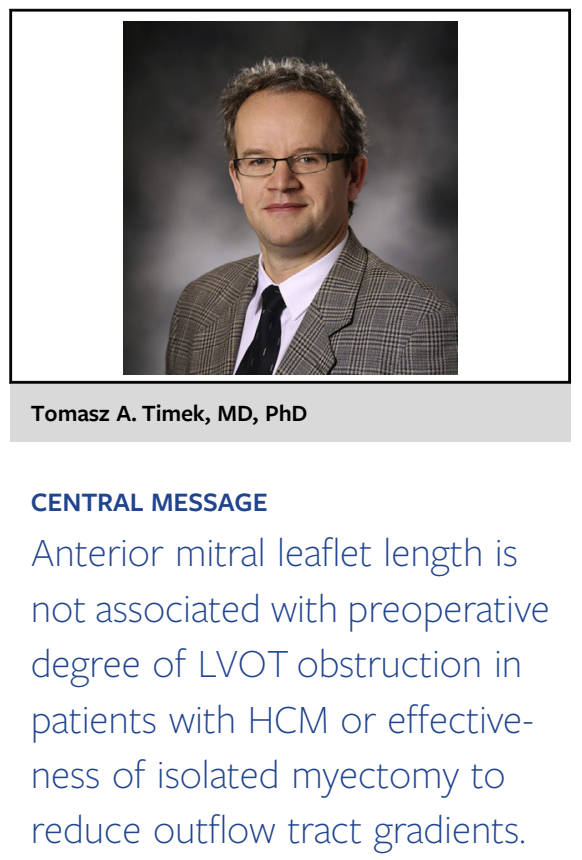

suggested that patients with longer anterior leaflets may experience greater relief of LVOT obstruction after isolated myectomy, ${ }^{8}$ corroborating concepts behind surgical anterior leaflet extension proposed by some surgeons. ${ }^{9}$ In a magnetic resonance imaging study of patients with HCM with LVOT obstruction and septal thickness of $18 \mathrm{~mm}$ or less, $\mathrm{Pa}-$ tel and colleagues ${ }^{1}$ found anterior leaflet length to be an independent predictor of maximal LVOT gradient along with basal thickness and bifid papillary muscle tip mobility. At surgery, $52 \%$ of these patients required additional nonmyectomy procedures, in stark contrast to the current report, although the basal septal thickness in $67 \%$ of patients requiring additional procedures was less than $15 \mathrm{~mm}$. Likewise, Sherrid and colleagues ${ }^{10}$ recommend routine anterior mitral leaflet plication in addition to myectomy in patients with obstructive HCM with relatively thin septa and anterior leaflet length of $30 \mathrm{~mm}$ or more. On the other hand, the Mayo group previously demonstrated that isolated myectomy is sufficient to treat LVOT obstruction in patients with thin septa $(<18 \mathrm{~mm}) .{ }^{11}$ The current data convincingly demonstrate that excess anterior leaflet length (>30 mm) does not diminish the success of surgical myectomy to relive LVOT obstruction, but resolution of SAM may be more complete in patients with leaflet length of less than $30 \mathrm{~mm}$. However, only resting gradient data are given by the authors, and it is feasible that clinically significant SAM and LVOT obstruction may become increasingly divergent between the elongated and nonelongated leaflet groups under stress conditions. Papillary muscle 
mobilization and division of abnormal chordal attachment is a described component of the surgical myectomy at the Mayo clinic ${ }^{12}$ while still considered an isolated procedure. The authors do not provide operative details whether all, some, or none of the patients in the current series underwent papillary muscle mobilization, but such intervention could contribute to relief of SAM along with extensive myectomy. Papillary muscle anatomy and geometry are increasingly recognized as intimately associated with obstructive HCM, particularly anatomic anterior displacement. Experimental anterior displacement of papillary muscles in normal dog hearts ${ }^{13}$ has been shown to induce SAM and LVOT obstruction, and papillary muscle realignment has been shown to alleviate SAM persisting after myectomy ${ }^{14}$ or arising after degenerative mitral valve repair. ${ }^{15}$ These studies suggest that leaflet geometry and position can be altered by subvalvular interventions. Conversely, majority of patients who underwent percutaneous alcohol septal ablation for obstructive HCM had persistent SAM, although significant LVOT gradient reduction was observed. ${ }^{16}$

The current data add to already substantial evidence supporting the "minimalist" approach to LVOT obstruction in patients with HCM using isolated myectomy promoted by the Mayo group. Even in the setting of an elongated anterior mitral leaflet, an appropriately performed myectomy deep into the ventricle appears to suffice.

\section{References}

1. Patel P, Dhillon A, Popovic ZB, Smedira NG, Rizzo J, Thamilarasan M, et al. Left ventricular outflow tract obstruction in hypertrophic cardiomyopathy patients without severe septal hypertrophy: implications of mitral valve and papillary muscle abnormalities assessed using cardiac magnetic resonance and echocardiography. Circ Cardiovasc Imaging. 2015;8:e003132.

2. Varghese R, Itagaki S, Anyanwu AC, Trigo P, Fischer G, Adams DH. Predicting systolic anterior motion after mitral valve reconstruction: using intraoperative transoesophageal echocardiography to identify those at greatest risk. Eur J Cardiothorac Surg. 2014;45:132-8.
3. Maron MS, Olivotto I, Harrigan C, Appelbaum E, Gibson CM, Lesser JR, et al. Mitral valve abnormalities identified by cardiovascular magnetic resonance represent a primary phenotypic expression of hypertrophic cardiomyopathy. Circulation. 2011;124:40-7.

4. Balaram SK, Ross RE, Sherrid MV, Schwartz GS, Hillel Z, Winson G, et al. Role of mitral valve plication in the surgical management of hypertrophic cardiomyopathy. Ann Thorac Surg. 2012;94:1990-7.

5. Carvalho JL, Schaff HV, Nishimura RA, Ommen SR, Geske JB, Lahr BD, et al. Is anterior mitral valve leaflet length important in outcome of septal myectomy for obstructive hypertrophic cardiomyopathy? J Thorac Cardiovasc Surg. 2023;165: 79-87.e1.

6. Ro R, Halpern D, Sahn DJ, Homel P, Arabadjian M, Lopresto C, et al. Vector flow mapping in obstructive hypertrophic cardiomyopathy to assess the relationship of early systolic left ventricular flow and the mitral valve. J Am Coll Cardiol. 2014 64:1984-95.

7. Jiang L, Levine RA, King ME, Weyman AE. An integrated mechanism for systolic anterior motion of the mitral valve in hypertrophic cardiomyopathy based on echocardiographic observations. Am Heart J. 1987;113:633-44.

8. Kuć M, Kumor M, Kłopotowski M, Dąbrowski M, Kopyłowska-Kuć N, Kołsut P, et al. Anterior mitral leaflet length and mitral annulus diameter impact the echocardiographic outcome after isolated myectomy. J Cardiothorac Surg. 2019;14: 212.

9. Vriesendorp PA, Schinkel AF, Soliman OI, Kofflard MJ, de Jong PL, van Herwerden LA, et al. Long-term benefit of myectomy and anterior mitral leaflet extension in obstructive hypertrophic cardiomyopathy. Am J Cardiol. 2015;115: 670-5.

10. Sherrid MV, Balaram S, Kim B, Axel L, Swistel DG. The mitral valve in obstructive hypertrophic cardiomyopathy: a test in context. J Am Coll Cardiol. 2016;67: 1846-58.

11. Nguyen A, Schaff HV, Nishimura RA, Dearani JA, Geske JB, Lahr BD, et al. Does septal thickness influence outcome of myectomy for hypertrophic obstructive cardiomyopathy? Eur J Cardiothorac Surg. 2018;53:582-9.

12. Kotkar KD, Said SM, Dearani JA, Schaff HV. Hypertrophic obstructive cardiomyopathy: the Mayo Clinic experience. Ann Cardiothorac Surg. 2017;6:329-36.

13. Levine RA, Vlahakes GJ, Lefebvre X, Guerrero JL, Cape EG, Yoganathan AP, et al. Papillary muscle displacement causes systolic anterior motion of the mitral valve. Experimental validation and insights into the mechanism of subaortic obstruction. Circulation. 1995;91:1189-95.

14. Bryant R, Smedira NG. Papillary muscle realignment for symptomatic left ven tricular outflow tract obstruction. J Thorac Cardiovasc Surg. 2008;135:223-4.

15. Sakaguchi T, Hiraoka A, Ryomoto M, Sekiya N, Tanaka H, Yamamura M. Papil lary muscle reorientation for systolic anterior motion after mitral valve repair. Ann Thorac Surg. November 4, 2020 [Epub ahead of print].

16. Delling FN, Sanborn DY, Levine RA, Picard MH, Fifer MA, Palacios IF, et al Frequency and mechanism of persistent systolic anterior motion and mitral regurgitation after septal ablation in obstructive hypertrophic cardiomyopathy. Am J Cardiol. 2007;100:1691. 